\title{
El Teatro Bolívar y otros espacios para las representaciones escénicas en Medellín, 1850-1950*
}

\section{Nancy Yohana Correa Serna}

Historiadora de la Universidad de Antioquia (Colombia). Magíster en Historia y estudiante del Doctorado en Historia de la Universidad Nacional de Colombia, sede Medellín (Colombia). Integrante del grupo de investigación Prácticas, saberes y representaciones en Iberoamérica (Categoría C de Colciencias). Sus investigaciones han girado alrededor de la historia de la participación femenina en las artes escénicas y de los espacios y representaciones teatrales en los siglos XIX y XX en Medellín. Autora de los siguientes capítulos de libros: "Una saga de cómicas, más de cincuenta años en escena. Las Ughetti, Esperanza Aguilar de Ughetti, Marina y Esperanza Ughetti, herederas de un oficio". En Perspectivas de género. Historia, actualidades y retos desde una óptica interdisciplinaria, coordinado por Oliva Solís Hernández y Norma Gutiérrez Hernández (Querétaro, México: Universidad Autónoma de Querétaro, 2015, 786 - 797); "Mujeres en escena. Espectáculos, itinerarios y compañías de teatro en Medellín entre la segunda mitad del siglo XIX y la primera del XX”. En Memorias Congreso Colombiano de Historia. XVII CCH. La paz en perspectiva histórica, coordinado por Darío Campos (Medellín: Asociación Colombiana de Historiadores, 2016, 21 - 40). Correo electrónico: nycorreas@ unal.edu.co

Referencia para citar este artículo: Correa Serna, Nancy Yohana. "El Teatro Bolívar y otros espacios para las representaciones escénicas en Medellín (1850 - 1950)". Historia y Espacio 47 (2016): 41-65.

\footnotetext{
* Artículo Tipo 2: de reflexión según clasificación de Colciencias. Hace parte de la tesis de Doctorado en Historia titulada “De las tablas al estudio de grabación. Mujeres en escena en Colombia, 1850-1950”, la cual está en proceso de construcción. No cuenta con financiación para su realización.
} 


\section{El Teatro Bolivar y otros espacios para las representaciones escénicas en Medellín, 1850-1950}

Resumen: Durante la primera mitad del siglo XX, el Teatro Bolívar fue el principal escenario para las representaciones teatrales, de ópera, de zarzuela y de otras actividades artísticas en Medellín. Pese a su importancia en el universo sociocultural de la ciudad, los historiadores de las artes escénicas, por lo regular, refieren del escenario algunos datos puntuales, proporcionados por los cronistas de la época, y presentan información fragmentaria sobre las condiciones del recinto, el aforo y otros aspectos relacionados con las compañías que allí trabajaron. Este artículo tiene como propósito ampliar el conocimiento sobre las transformaciones de este escenario, desde la inauguración del primer Coliseo de la ciudad hasta su demolición y la posterior construcción del Teatro Bolívar en el mismo lugar. Además, se tendrán en cuenta otros espacios dispuestos para las representaciones escénicas en Medellín, al describir la aparición, la transformación y la trascendencia que alcanzaron dichos escenarios en el acontecer cultural local, del cual fueron testigos y protagonistas.

Palabras claves: Medellín, escenarios, Teatro Bolívar, Circo Teatro España, Teatro Junín.

\section{The Teatro Bolivar and other spaces for the theatrical representations in Medellín (1850-1950)}

Abstract: During the first half of the twentieth century, the Teatro Bolivar was the main stage for theater, opera, zarzuela and other artistic activities in Medellin. Despite its importance in the socicultural universe of the city, historians of the performing arts, usually, understand the scenario based only in some specific facts, provided by the writers of the time, and have unfocussed information about conditions in the enclosure, the capacity and other aspects related to the companies involved. The main purpose of this article is to brad the knowledge about the transformations in this scenario, since the inauguration of the first Coliseo in the city until its demolition and subsequent construction of the Teatro Bolívar in the same place. Also we take into account other spaces provided for stage performances in Medellin, describing the rising, transformation and transcendence that reached these scenarios in the local cultural dynamics, which were witnesses and main actors.

Keywords: Medellin, Stages, Teatro Bolívar, Circo Teatro España, Teatro Junín.

\section{O Teatro Bolívar e outros espaços para as representações cênicas em Medellín (1850 - 1950)}

Resumo: O Teatro Bolívar, durante a primeira metade do século XX, foi o palco principal para as representações teatrais, de ópera, de zarzuela e de outras atividades artísticas em Medellín. Apesar de sua importância no universo sociocultural da cidade, os historiadores das artes cênicas, frequentemente, referem sobre o Teatro dados específicos fornecidos pelos cronistas da época, e apresentam informação fragmentada sobre as condições do recinto, o aforo e outros aspectos relacionados com as companhias que ali trabalharam. Este artigo tem o objetivo de ampliar o conhecimento sobre as transformações desse cenário, desde a abertura do primeiro Coliseu da cidade até sua demolição e a construção posterior do Teatro Bolívar no mesmo local. E ainda, serão levados em conta outros espaços dispostos para as representações cênicas em Medellín, ao descrevermos o aparecimento, transformação e transcendência desses lugares no âmbito cultural da cidade, do qual foram testemunhas e protagonistas.

Palavras-chave: Medellín, cenários, Teatro Bolívar, Circo Teatro España, Teatro Junín. 


\section{Introducción}

Debido a los escasos espacios de sociabilidad y esparcimiento que poseía Medellín a mediados del siglo XIX, el teatro se convirtió en una "culta” diversión para los habitantes de esta ciudad. Fue recurrente que los cronistas locales consideraran las artes escénicas como una herramienta pedagógica que debía tener como objetivo transformar la conducta social y privada de las personas, llevándola a niveles más elevados de civilidad y urbanidad, pues, tal como expresa la estudiosa del tema Marina Lamus Obregón, en dicho siglo se consideraba que el grado de desarrollo de las bellas artes revelaba el grado de "civilización” o de "barbarie" de un país ${ }^{1}$. Los columnistas de los periódicos locales defendieron la idea de que a través de las tablas se fomentaban los nuevos "paradigmas de las naciones civilizadas", en los cuales se abogaba por una transformación interior de los individuos, que modelaban su comportamiento en los espacios públicos. En consecuencia, las compañías escénicas estaban en la obligación de contribuir con la formación del buen gusto del respetable público, que se componía de lo más selecto de una población que, para ese entonces, sumaba 14.800 habitantes².

No obstante, para que el teatro pudiera realizar su elevada misión social, debía contar con espacios adecuados para las nuevas necesidades de las compañías. El primer teatro de Medellín, llamado Teatro Principal o Coliseo, se fundó en 1836 y perduró hasta 1917, cuando sobre el viejo edificio se construyó el Teatro Bolívar, que podía albergar 1.200 espectadores. Hasta su demolición en 1954, este espacio fue el principal teatro de la ciudad por su aforo, sus condiciones acústicas, el telón de boca, los decorados y la disposición de la caja escénica, que le permitían a las compañías ofrecer espectáculos de mayor calidad.

Este artículo busca comprender el significado social del Teatro Bolívar y de otros espacios para las representaciones escénicas en Medellín durante un siglo: de 1850 a 1950. Se sostiene que, gracias a la mediación del teatro, los espectadores construyeron una representación de ellos mismos, una comprensión de lo social y una interpretación de sus relaciones con el mundo. La perspectiva

1 Marina Lamus Obregón, Teatro siglo XIX. Compañías nacionales y viajera (Bogotá: Kimpres, 2004), 21.

2 “Censos del Distrito de Medellín”, El Colombiano, Medellín, 10 de octubre, 1918, 2. 
analítica que orienta el presente texto se enmarca dentro la historia cultural, que aquí se entiende como la "historia de las prácticas y las representaciones y pone su acento y su mayor atención en el estudio de las lógicas y las racionalidades, que se tejen en determinados grupos humanos"3. La perspectiva permitió analizar el teatro como un espacio de sociabilidad, el cual fue privilegiado por las elites económicas y culturales de la ciudad, para poner en circulación, de manera rápida y masiva, representaciones sociales que se ajustarán al proyecto de modernización, coherente con el proceso de crecimiento económico derivado del desarrollo industrial.

De esta manera, un producto cultural como el teatro posibilitó acercarse, a través de un abordaje diferente al tradicionalmente realizado por los estudiosos del tema, a problemas sociales desde una óptica poco explorada por la disciplina histórica en nuestro país. El periodo estudiado corresponde con la permanencia del Teatro Bolívar en la ciudad y las principales fuentes para su estudio fue la prensa, que por lo regular reseñaba las representaciones escénicas que allí se llevaban a cabo; las actas del Concejo Municipal, que era la corporación que legislaba sobre los espectáculos públicos y que además tenía acciones en el teatro; las revistas culturales, que abordaban el acontecer cultural local; cronistas de la época (como Eladio Gónima) y bibliografía especializada que permitió comprender el problema desde una dimensión más amplia.

\section{El Teatro Principal o Coliseo: una iniciativa cultural privada en el siglo XIX}

Durante sus ochenta años de funcionamiento, el Coliseo o Teatro Principal fue objeto de múltiples reformas y reparaciones a medida que las circunstancias lo iban exigiendo. Una de las transformaciones más importantes, coherente con el proyecto de cambio de costumbres de los asistentes, fue retirar del edificio el establecimiento de riñas de gallos, lugar frecuentado por un tipo de público distinto al que se pretendía que siguiera los dictados, la estética, los modales, las formas de relación social, las modas y los objetivos civilizadores impuestos por las elites económicas y culturales de la ciudad $^{4}$.

La apariencia del teatro fue tan sólo uno de los elementos con los que se procuraba medir el nivel de "progreso" y "civilización" de la sociedad de Medellín en el transcurso del siglo XIX al XX. A medida que la ciudad crecía y las instancias del gobierno local reglamentaban la vida en común ${ }^{5}$ y el desarrollo urbanístico y arquitectónico, el teatro fue objeto de diferentes adecuaciones, que hablan

3 Diana Luz Ceballos Gómez, “Introducción. Prácticas, saberes y representaciones: una historia en permanente construcción”, en Prácticas, territorios y representaciones en Colombia, 1849-1960 (Medellín: Universidad Nacional de Colombia, 2009), 23.

4 Nancy Yohana Correa Serna, “Teatro y sociedad en Medellín, 1880 -1910” (Tesis de pregrado, Departamento de Historia, Universidad de Antioquia, 2004).

5 Jaime Alberto Gómez Espinosa, “Ordenando el orden: la policía en Medellín 1826-1914. Funciones y estructuras" (Tesis de pregrado, Maestría en Historia, Universidad Nacional de Colombia, sede Medellín, 2012). 
sobre la disposición racional de los lugares, lo que Luis Fernando González ha denominado "arquitectura higiénica"6.

El Teatro Principal o Coliseo fue inaugurado en 1836 en la calle Ayacucho, entre Junín y Sucre gracias a la gestión de Pedro Uribe Restrepo ${ }^{8}$, quien al parecer estuvo madurando la idea de dotar a la ciudad de un espacio adecuado para representaciones teatrales desde su regreso de Europa en 1834. Este médico y promotor de obras cívicas reunió a otros “notables" conciudadanos como los señores Francisco A. Gónima y Llano, Fermín Isaza, Miguel Tello, José Ma. Carrasquilla, Sebastián Amador, Apolinar Villa y Francisco Ortega ${ }^{9}$ con el fin de darle inicio a la obra, que tuvo un costo aproximado de \$12.300 pesos oro. Los planos fueron realizados por él mismo y la construcción estuvo a cargo de los maestros Vicencio y Januario Ortiz, N. Muñoz, Alzate y Morales. El edificio poseía un escenario de unos dieciséis metros de frente por diez de fondo ${ }^{10} \mathrm{y}$, desde sus inicios, contó con una taberna y un patio central descubierto, utilizado cuando no había representaciones teatrales para las riñas de gallos; esta disposición espacial obligaba al público asistente a funciones dramáticas a ausentarse en las noches de lluvia. La casa anexa al Teatro la ocupó por varios años el señor José María Carrasquilla, a quien se le encargó la administración del mismo ${ }^{11}$.

Décadas después de su inauguración, el Coliseo contó entre sus espectadores con el médico y botánico francés Charles Saffray, quien en su libro Viaje a Nueva Granada dedicó un espacio para describir el teatro y retratar sus impresiones sobre el espectáculo. Saffray arribó a Medellín en 1861 y, después de hacer referencia sobre algunas costumbres de los habitantes y el funcionamiento del comercio, afirmó que:

En Medellín hay un coliseo que tiene dos filas de palcos; la platea es bastante grande, pero no hay asientos; allí se pasea el público libremente y fuma sin temor que se vicie la atmósfera, pues el techo es pura y sencillamente la celeste bóveda; el arquitecto hubo de renunciar a ponerle por falta de los materiales necesarios. Todos los actores pertenecen al sexo feo; ninguna mujer se atrevería a presentarse en las tablas; y si hubiese alguna capaz

\footnotetext{
6 Luis Fernando González, “La fisiología de la ciudad: médicos e ingenieros en el Medellín de hace un siglo”, en Iatreia, 19: 1 (2006). 77 - 94 .

7 Patricia Londoño Vega, “Vida diaria en Antioquia durante el siglo XX”, en Historia de Antioquia, ed. Jorge Orlando Melo (Medellín: Suramericana de Seguros, 1987), 190.

8 Pedro Uribe Restrepo nació en Envigado en 1787, realizó sus estudios de medicina en Europa y a su llegada, hacía 1836, tuvo la iniciativa de fundar un teatro; impulsó también la creación del Cementerio de San Pedro en 1842, de un hospital y de la primera farmacia de Medellín. Isidoro Silva, Primer directorio general de la ciudad de Medellín, para el año de 1906 (Medellín: Instituto Tecnológico Metropolitano, 2003) 97-100.

9 Eladio Gónima, Historia del teatro de Medellín y vejeces (Medellín: Ediciones Tomás Carrasquilla, 1973), 9.

10 “Teatro", La Balanza, 8 de julio, 1880, 107.

11 Eladio Gónima, Historia del teatro, 24.
} 
de arrostrar las preocupaciones y la excomunión, la falta de señoras protestaría contra semejante escándalo ${ }^{12}$.

Si bien el techo del Coliseo sólo se instaló años después, en las tablas del mismo ya se había presentado la primera actriz local, Susana Tirado. La artista subió a escena en 1857 y perteneció a la Sociedad Dramática de Medellín, agrupación con la cual actuó entre dicho año y $1859^{13}$ y posteriormente, trabajó con la Compañía Dramática Española Luque en $1864^{14}$ y 1866 . Aunque Tirado obtuvo reconocimiento por su trabajo y dotes artísticas, no logró vivir de la profesión actoral y terminó condenada a la indiferencia y al anonimato en la ciudad, en parte, por lo que Saffray señalaba: la intolerancia de la sociedad medellinense frente al ejercicio por parte de una mujer del oficio de actriz.

A medida que la ciudad fue creciendo -hacia 1869 contaba con una población aproximada de 29.765 personas ${ }^{15}$ - y con el arribo de algunas compañías extranjeras, el "cascarón" -tal como los periodistas denominaban al Coliseo- , fue objeto de algunas reparaciones, entre éstas la cubierta del patio realizada por Mariano Luque, empresario y director de una compañía de teatro con la que había llegado a Medellín en $1864^{16}$. Dicha adecuación se mejoró veinte años después, cuando el techo fue reforzado con amarres de lazos de fique ${ }^{17}$.

Sin embargo, el ajuste no contentó a los cronistas culturales, quienes desde sus columnas en la prensa local insistieron en la necesidad de acondicionar apropiadamente el espacio, inversión que debían asumir en su totalidad los dueños del teatro y no las compañías que lo alquilaban. Para el diario El Índice, "No dudará nadie, pues, de que no tenemos teatro porque los señores propietarios son perezosos para gastar algunos reales en su propio beneficio, i [sic.] que al paso que vamos, pronto, mui [sic.] pronto del actual edificio no quedará sino el CAMPO DONDE FUÉ"18. En este sentido, solicitaban a los empresarios que, como mínimo, pintaran el edificio y organizarán el nivel del patio, a la vez que instaban al gobierno local a construir un nuevo Coliseo, el cual contribuiría al "ornato de la población” ${ }^{19}$.

El teatro debía integrarse al proceso de reforma de las costumbres consideradas "atrasadas". Los periodistas locales insistieron en la necesidad de prohibir la venta de licores dentro del recinto ${ }^{20}$ y de evitar arrendarlo para las riñas de gallos, actividad considerada como "bárbaro i [sic.] extravagante

12 Charles Saffray. Viaje a Nueva Granada (Bogotá: Ministerio de Educación Nacional, 1948), 108. Saffray emprendió su viaje por la Nueva Granada en 1861 y publicó su relato Voyage à la Nouvelle Grenade en la revista Le Tour du Monde entre 1872 y 1873.

13 Marina Lamus Obregón, Teatro siglo XIX, 137-38.

14 "Teatro", El Correo de Antioquia, 21 de julio, 1864, 3.

15 “Censos del Distrito de Medellín”, El Colombiano, 10 de octubre, 1918, 2.

16 “Teatro", El Correo de Antioquia, 6 de agosto, 1864, 10.

17 “Teatro", La Balanza, 8 de julio, 1880, 107.

18 "El Teatro en Medellín", El índice, 15 de abril, 1865, 12

19 "Teatro", El 5 de abril, 16 de agosto, 1877, 27.

20 A. E, "Revista de Teatro", Antioquia, 5 de noviembre de 1857, 20. 
espectáculo [...] que solo pudo tener orijen [sic.] en el barbarismo español o en la extravagancia inglesa”21. Para el funcionamiento de la gallera, según indica Lisandro Ochoa en Cosas viejas de la Villa de la Candelaria, "se retiraba parte del lunetario y se colocaba en el centro un redondel bajo, de madera, donde tenían los gallos sus disgustos, acompañados de juez y careadores"22. Esta actividad, a pesar de ser considerada por los defensores de la cultura y el progreso como contraria al cambio en el comportamiento individual en espacios tanto públicos como privados, se mantuvo en el Teatro Principal hasta finales del siglo XIX. Por su parte, la cantina, a la cual se le sumó un restaurante después de la construcción del nuevo edificio en 1917, permaneció hasta la demolición definitiva del teatro.

Hacia la década de 1880, los nuevos propietarios, Cipriano Isaza, Boteros \& Cía. y Gregorio Arango B. ${ }^{23}$, realizaron algunas remodelaciones al Coliseo, para atender las necesidades de una ciudad que sumaba 37.237 pobladores en $1883^{24}$. De esta manera, en 1884 , se anunciaba, por medio del periódico El Liceo Antioqueño, que "en el elegante y cómodo teatro recién construido" se llevaría a cabo un concierto a beneficio de las casas de caridad ${ }^{25}$.

Algunas incomodidades señaladas por los periodistas y el alto costo del alquiler del escenario condujeron a que otros espacios fueran utilizados para la representación de obras de teatro. Anacleto Mesa, a través del periódico El Ciudadano, promocionaba su casa para tal efecto de la siguiente manera: "el edificio ofrece comodidades por estar refaccionado i apropiado para el objeto; buen gusto en la elección de las piezas i [pequeñas] piezas que allí se representen, esmero en los actores, i [sic.] deseo de complacer al público - sobre todo un cuerpo de policía para sostener el órden i [sic.] una magnifica sala buena para baile, que se arrienda a un precio ínfimo" ${ }^{26}$. Dos servicios proporcionados por Mesa llaman la atención al aludir a formas de disciplinar al público asistente: en primer lugar, la alusión al "buen gusto" en la elección de las piezas, que parece referirse al hecho de que el repertorio solamente incluyera aquellas obras que contribuyeran a consolidar los valores y las normas consideradas “cultas” en la época. En segundo lugar, la presencia de la policía, que se encargaría del control de los cuerpos y los comportamientos durante las representaciones y los bailes.

Así mismo, por iniciativa del vallecaucano Lino Ricardo Ospina y el payanés Francisco Vidal, en 1884, se acondicionó como teatro un local situado en una casa amplia ubicada en la calle Junín, propiedad de la señora Mariana Arango, al cual denominaron “Teatro de Variedades”. Según la prensa local, el lugar tenía la capacidad de albergar aproximadamente quinientos espectadores y poseía

21 El dairiador. "Crónica Teatro", El Índice, 11 de febrero, 1866, 109

22 Lisandro Ochoa, Cosas viejas de la villa de la Candelaria (Medellín: Colección Autores Antioqueños, Vol. 8, 1984), 38.

23 Lisandro Ochoa, Cosas viejas de la villa de la Candelaria, 38.

24 “Censos del Distrito de Medellín”, El Colombiano, 10 de octubre, 1918, 2.

25 “Teatro", El Liceo Antioqueño, 15 de septiembre de 1884, 112.

26 "Funciones de Teatro, casi gratis", El Ciudadano, 15 de abril, 1875, 48. 
un techo sólido y adecuada ventilación ${ }^{27}$. Allí se presentaron, por dicha época, la Compañía Lírico Dramática Infantil, la compañía Fernández Birelli, la Compañía de Martín A. Gómez y una compañía de aficionados en 1890, lo cual es indicio de que dicho local se mantuvo en funcionamiento hasta la última década del siglo XIX ${ }^{28}$.

Por su parte, el empresario teatral italiano Mario Lambardi ${ }^{29}$, después de culminar la temporada de ópera de su compañía en el Teatro Principal en 1892, se radicó en la ciudad con el objetivo de construir un teatro, que albergara a la troupe de fantoches de la cual era director Juan Dell'Acqua. El nuevo proscenio se levantó en la calle Junín, banda derecha de la quebrada Santa Elena. Para el diario El Espectador, éste poseía "condiciones de solidez y durabilidad completamente satisfactorias. Gracioso y elegante, cómodo y espacioso, y de tanta capacidad por lo menos como nuestro viejo Coliseo [...]. Tiene buen escenario, platea para centenares de asistentes, dos filas de palcos bien desahogados, paraíso amplio, donde si puede andar cualquiera, con la cabeza alta y, en fin, cuantas comodidades son compatibles con el carácter de improvisación que tiene”30. Pese a sus condiciones aceptables, no se tiene noticia de su permanencia en la escena cultural de Medellín.

Por esta época, los signos de modernización proliferaban en la ciudad. Existían dos bancos: el Banco de Medellín creado en 1881 y el Banco Popular de Medellín establecido un año después. Se había fundado la Sociedad de San Vicente de Paul en 1882; se organizó la Escuela de Música Santa Cecilia en 1888; se inauguró el Parque Bolívar en 1892, y se constituyeron la Compañía de Instalaciones Eléctricas en 1895 y la Sociedad de Mejoras Públicas en 1899. Mientras tanto, el Teatro Principal, pese a ser el mejor de su época, seguía siendo blanco de los periodistas por su deteriorado aspecto y la falta de iluminación, la cual era generada por lámparas incandescentes.

Los reiterados comentarios publicados en la prensa obligaron a los dueños a encomendar a José Antonio Arango, hacia 1899, la realización de algunas reparaciones y reformas en el recinto ${ }^{31}$ pues, para los cronistas culturales, el teatro contaba "con un alumbrado medioeval, un escenario feo y estrecho en sumo grado, sin salón para fumar y con una sola entrada, angosta por demás" ${ }^{2}$. Un nuevo elemento cultural apareció en esta época, cuando se empezó a evidenciar la necesidad de eliminar el consumo de cigarrillo durante las representaciones teatrales; para tal efecto se exigió la construcción de un espacio apropiado para fumar, alejando esta práctica del escenario, pues el humo de las lámpa-

27 “Teatro de Variedades", El Liceo Antioqueño, 16 de junio, 1884, 15.

28 Nancy Yohana Correa Serna, “Teatro y sociedad”, 60.

29 Francisco Zenardo fue fundador del Teatro Municipal de Bogotá en 1890, actualmente Teatro Municipal Jorge Eliécer Gaitán.

30 "Nuevo Teatro", El Espectador, 30 de julio, 1892, 373.

31 Cenedith Herrera, “Entre máscaras y tablas. Teatro y sociedad en Medellín, 1890-1950” (Tesis de pregrado, Departamento de Historia, Universidad Nacional de Colombia-Sede Medellín, 2005), 107. Consúltese en este trabajo la transcripción del periódico El Cascabel sobre las reformas que se le hicieron al edificio en 1899.

32 Las Novedades, 19 de septiembre, 1896, 623. 
ras y de los tabacos impedía el buen desempeño de los artistas; además, esperar a un entreacto para fumar contribuía a educar el cuerpo y a transformar las reglas de comportamiento en general. Al parecer, esta costumbre fue casi imposible de erradicar, pues aún en 1944 algunas compañías se veían obligadas a solicitar al público en su publicidad no fumar durante la representación. La solicitud de un salón para fumar correspondía con un espacio tradicional de las casas elegantes para tal efecto, el cual fue un lugar común de sociabilidad masculina.

Para terminar de deteriorar la situación del viejo teatro, en 1904, sucumbió bajo las llamas y sólo volvió a habilitarse dos años más tarde. En esta década, el discurso salubrista había cobrado bastante fuerza gracias a los esfuerzos divulgadores de la Academia de Medicina de Medellín, razón por la cual, tras la reinauguración del Coliseo, se llamó la atención sobre la necesidad de cambiar de sitio los aseos, ya que los olores perjudicaban la higiene de todo el recinto, en el cual los periodistas señalaban: "lo primero que se percibe son los amoniacales efluvios de los excusados" ${ }^{3}$. En adelante, se presentaron varias iniciativas para mejorar el viejo Coliseo: la Sociedad de Mejoras Públicas manifestó, en 1908, la intención de comprar el teatro, organizarlo y explotarlo ${ }^{34}$ y, por otra parte, el Presidente de la República, General Rafael Reyes, ofreció una gran suma de dinero para construir un nuevo escenario con el fin de conmemorar el inminente centenario de la independencia de Antioquia ${ }^{35}$. Ninguna de las dos propuestas se materializó, pese al entusiasmo de los periodistas locales, quienes aseguraban que "tenemos que convencernos de que un buen Teatro es el mejor signo de progreso que pueda mostrar en el día esta pobre Parroquia nuestra, y de que los que inicien su construcción serían dignos de toda estimación y de todo aplauso"36.

La ciudad tuvo que esperar unos años más para poder estrenar un Coliseo acorde con su nivel de "progreso", el cual se hacía notorio en el incremento acelerado de su población, pues en 1905 ya habitaban en la ciudad 59.815 personas $^{37}$ y en 1912, la población alcanzaba los 70.547 habitantes ${ }^{38}$. Dicho crecimiento, aunque de manera más moderada, también se denotaba en los aspectos urbanístico y arquitectónico, ya que, en 1911, el paisaje urbano, de acuerdo con el periódico El Conservador, se componía de " 4.457 casas de un piso, 198 casas de dos pisos, 28 casas de tres pisos, 10 casas de cuatro pisos, 1 teatro propiedad particular, 1 circo propiedad particular, 2 plazas de mercado cubierto, 1 catedral, 7 iglesias, 4 capillas, 1 catedral en construcción, 2 iglesias en construcción. De estos

\footnotetext{
33 "Notas", La Luneta, 3 de julio, 1906, 3.

34 “De Teatro", Helios, 26 de septiembre de 1908, 2.

35 "Nuevo Teatro", Helios, 31 de octubre, 1908, 2.

36 "De Teatro", Helios, 26 de septiembre, 1908, 2.

37 “Censos del Distrito de Medellín”, El Colombiano, 10 de octubre, 1918, 2.

38 "Censo probable de Medellín", El Colombiano, 3 de octubre, 1918, 2.
} 
edificios 17 son propiedad del Departamento, 6 del Municipio y 1 de la Nación”39. El circo citado en el inventario de edificios de Medellín es el Circo Teatro España, el cual se construyó en 1909 con capacidad para seis mil espectadores y donde se presentaban obras de teatro y zarzuela, cine y otros espectáculos, como corridas de toros y circos. El escenario sufrió múltiples averías tras un incendio de su carpa a finales de 1930 y nueve años después fue demolido para dar paso a construcciones más modernas $^{40}$, como la plaza de toros La Macarena inaugurada hacia 1945 que, aunque no se hallaba en el mismo lugar, se erigió para los mismos fines del circo.

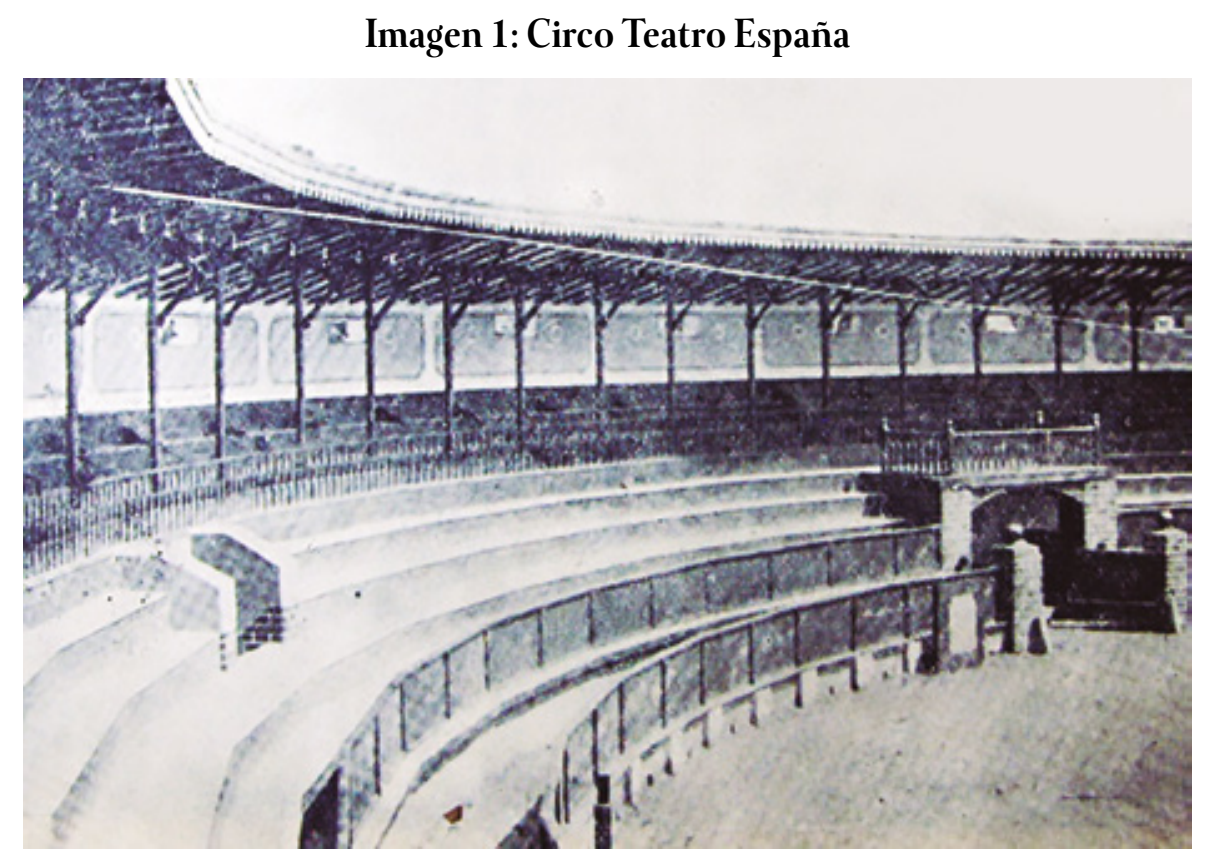

Fuente: Sábado, Medellín, julio 1,1922, número 52, p. 623.

Con el fin de cumplir con el cometido de obtener un nuevo teatro, algunos protagonistas de la escena cultural local realizaron varias propuestas tendientes a reunir el dinero suficiente para tal propósito. Elías Gómez, gerente del Circo Teatro España, le propuso al Concejo de Medellín que aumentara en un centavo el impuesto a las cajetillas de cigarrillos y ofreció el Circo para realizar funciones mensuales a favor de dicha obra ${ }^{41}$. Ésta y otras iniciativas no fueron atendidas a corto plazo por las autoridades, quienes consideraban que la ciudad debía solucionar problemas más urgentes como el

39 "Dato importante. Edificios de Medellín”, El Conservador, Medellín, 6, 10 de octubre, 1911, 3.

40 E. Uribe Uribe, "El Circo España”, El Colombiano, 9 de diciembre, 1939, 5.

41 “Más sobre el teatro futuro", El Colombiano, 1 de mayo, 1913, 3. 
servicio de acueducto. Sin embargo, en 1916, los dueños del Coliseo acordaron con la Sociedad de Mejoras Públicas "un negocio según el cual se flotantiza la empresa y se introducen al edificio del Teatro las mejoras convenientes. La Empresa quedaría dividida en 5.000 acciones de a \$10 oro cada una; de éstas, 2.000 las tomarían los dueños del Teatro, y las sobrantes se ofrecerían en venta”2

El proyecto tuvo muy buena acogida: el Municipio tomó acciones por valor de $\$ 2.000$ oro $^{43}$, el Departamento de Antioquia compró 1.200 acciones de acuerdo con el artículo 2 de la Ordenanza 32 de $1917^{44}$ y se recibieron también donaciones, como la de un anónimo que escribió al periódico El Colombiano, ofreciendo el portón de hierro para aquel edificio, donación que haría con gusto pues se consideraba "bastante civilizado [...] uno de los caracteres distintivos del hombre culto obrar así con su ciudad”45. Por su parte, algunas empresas y personas de manera individual compraron acciones, que donaron a la Sociedad de Mejoras Públicas, entre ellas el Banco Alemán Antioqueño, Hijos de Alonso de Toro \& C., Enrique A. Gaviria, Juan Martínez y señora, Pablo Lalinde B. y Jorge Rodríguez L. ${ }^{46}$; acciones que, a mediados de 1917, sumaban alrededor de 136. Así mismo, el 4 de mayo de dicho año, se constituyó la Sociedad Compañía del Teatro Bolívar, la cual estaba compuesta por los comerciantes locales Manuel J. Álvarez, Ricardo Greiffestein y Ricado Olano, además del abogado Ricardo Uribe Escobar, quienes tenían por objetivo la construcción y la explotación de un teatro en Medellín, para lo cual contaban con $\$ 600$ oro, que se distribuyeron en seiscientas acciones de a un peso oro legal, en las cuales cada uno de los accionistas contaba con cien de ellas y; dejaron las doscientas restantes para la reserva de la compañía ${ }^{47}$ Se presume que tal compañía aportó su capital en el proyecto de construcción del Teatro Bolívar.

Una vez solucionado el problema de los recursos, la nueva Junta Directiva del Teatro acordó promover un concurso entre los arquitectos de toda la nación para el proyecto de la reforma del Coliseo. Al final, sólo se recibieron planos de Bogotá y con el proyecto escogido, iniciaron las obras en noviembre de 1917, bajo la dirección técnica de Horacio Marino Rodríguez y del maestro de obras Joaquín F. Vélez ${ }^{48}$. Meses después, el gerente de la nueva Compañía del Teatro Bolívar le recordaba al Concejo Municipal de Medellín que a partir del 1 de febrero de 1918 vencía el plazo para reembolsar un pagaré por \$ 5.000 oro a cargo del tesoro del distrito y a favor de dicha compañía. Teniendo en cuenta que en el momento la sociedad no necesitaba dicho dinero, pese a estar en construcción el

42 “Teatro Medellín", El Colombiano, 30 de septiembre, 1916, 2.

43 "Teatro Medellín", El Colombiano, 12 de octubre, 1916, 3.

44 "Teatro Bolívar", El Colombiano, 15 de junio, 1917, 2.

45 “Teatro-Medellín. Un generoso anónimo", El Colombiano, 9 de noviembre de 1916, 2.

46 "Para el Teatro Bolivar", El Colombiano, 1 de mayo, 1917, 2.

47 "Escritura pública No. 947" (Medellín, 4 de mayo de 1917), en Archivo Histórico de Antioquia (A.H.A.), Fondo Notarial, Notaría Primera, folios 2657-2659.

48 “Reconstrucción del Teatro Bolívar", El Colombiano, 21 de noviembre, 1917, 2. 
teatro, el Concejo acordó dejar al distrito la suma de dinero adeudada en una cuenta corriente al 12\% anual que, según el gerente, se retirarían en "cantidades no mayores de \$1.000 oro y con distancias de plazos no mayores de 30 días. Los intereses se pagarían al retirarse la última partida”49. Sobre el Teatro, el Concejo Municipal se volvió a pronunciar el 22 de marzo de 1919, con el fin de autorizar al personero de la ciudad a emitir un voto positivo en la asamblea general de accionistas de la Compañía del Teatro Bolívar, a razón de que el municipio era propietario de acciones por valor de $\$ 2.000$ oro. El voto suponía apoyar al gerente de la sociedad, para que hipotecara el teatro, si fuera necesario, "con el fin de conseguir un empréstito en cuenta corriente hasta por la cantidad de $\$ 15.000$ oro y terminar la construcción de la obra” ${ }^{50}$.

Así pues, la Compañía del Teatro Bolívar, como se denominaría el nuevo escenario, citaba a sus accionistas para tratar sobre la terminación del edificio y días después, se realizaron varias contrataciones para la decoración tanto interior como exterior del Teatro ${ }^{51}$. En total, la construcción y decoración de este espacio estuvo a cargo de cinco profesionales: los “arquitectos [...] fueron Dn. Horacio M. Rodríguez (parte interior) y Dn. Enrique Olarte (fachada). La decoración de la sala [fue] obra de Dn. Manuel García (español); la del arco armónico y del resto del teatro es de Dn. Víctor M. Martínez (de Bogotá), y la reforma del telón la hizo el pintor bogotano don Rafael Zerda, así como la decoración Luis XV que se exhibió la noche del estreno"52.

El escenario se habilitó el 31 de octubre de 1919, bajo la gerencia de Enrique Hernández y fue estrenado con un variado programa, que contó, entre otras puestas en escena, con la interpretación por parte de un grupo de ciudadanos aficionados, de la comedia "Paz Doméstica”, escrita por la dama de la sociedad medellinense Alicia Merizalde de Echavarría ${ }^{53}$, representación que se hizo a beneficio de las obras del Hospital de San Vicente de Paúl ${ }^{54}$. Así mismo, se presentaron días después el Arpa Colombiana y la Compañía Dramática de Zarzuela y Variedades Matilde Palou. El edificio remodelado contó con una capacidad similar a la del Teatro Colón de Bogotá: "trescientas ochenta plateas, treinta y dos palcos de a seis puestos, doscientas dos butacas de balcón, ciento cuarenta y cuatro asientos de galería numerados, doscientos sesenta puestos de galería sin numerar, y hasta cien personas en promenoir" 55 , espacio suficiente para albergar a los aficionados al teatro de una ciudad que alcanzaba los 70.000 habitantes.

49 Archivo Histórico de Medellín (A.H.M), Fondo Actas del Concejo Municipal, tomo 325, folio 80, 30 de enero, 1918.

50 A.H.M. Fondo Actas del Concejo Municipal, tomo 326, folio 85v, 22 de marzo, 1919.

51 "Un artista", El Espectador, 7 de mayo, 1919, 1.

52 "En el Teatro Bolívar", Colombia, Medellín, 12 de noviembre, 1919, 260.

53 Alicia Merizalde de Echavarría, casada con el industrial Ramón Echavarría Echavarría, escribió durante varios años para la revista femenina Letras y Encajes, de la cual fue directora. Letras y encajes, Medellín, 1926-1959.

54 "Teatro Bolívar", El Espectador, 4 de septiembre, 1919, 3.

55 Luis Emiro Mejía, “Visitas de Sábado. En el Teatro Bolívar”, Sábado, 28. de mayo de 1921, 29. 
Según el diario Colombia, la pieza dramática con la que fue estrenada el Teatro fue bien acogida por el público local, quienes reconocieron en ella una obra bien elaborada, natural, sin recursos forzados y con pasajes cómicos que lograron mantener la atención de los espectadores durante toda la función. Sobre el edificio opinaban que:

Cuenta hoy Medellín con un teatro bastante bueno por su capacidad, por su construcción y por el gusto y confort con que ha sido decorado. Es una sala muy presentable, con derroche de luz, con espléndidas condiciones acústicas, y que por muchos años puede servir lucidamente para nuestras escasas veladas teatrales. Débese esta importante mejora de la ciudad a la Honorable Asamblea del Departamento, al Concejo Municipal, a los propietarios del antiguo local, al esfuerzo incansable de la Sociedad de Mejoras Públicas, y a la labor constante y tesonera de Dn. José A. Gaviria, Gerente de la empresa y uno de los ciudadanos más dotados de espíritu público con que cuenta la ciudad ${ }^{56}$.

\section{Imagen 2: Fachada del Teatro Bolívar}

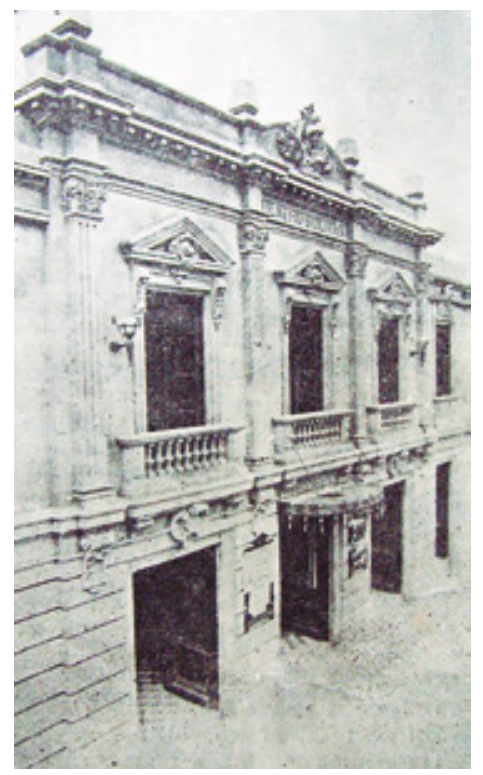

Fuente: Sábado, mayo 28, 1921, número 4, p. 29. 
Imagen 3: Interior del Teatro Bolivar

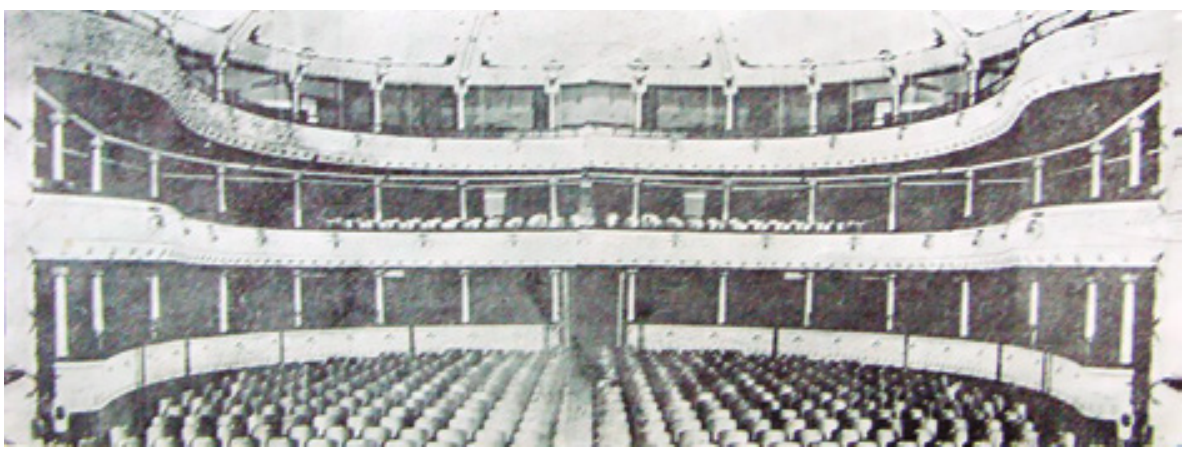

Fuente: Sábado, mayo 28, 1921, número 4, p. 29

\section{El Teatro Bolívar: una sociedad mixta}

Un año después del estreno del Teatro Bolívar, el periódico El Correo Liberal publicó una nota remitida por un anónimo que se quejaba del mal servicio de cantina y restaurante, al que consideraba "desastroso, sin aseo ni higiene", en el cual se servían las bebidas en copas sucias y con unos precios muy altos ${ }^{57}$. En los siguientes días, Isaac Londoño, en nombre de un grupo de ciudadanos entre los que figuraban algunos médicos, certificaba públicamente que las condiciones del recinto eran higiénicas y la atención excelente. Este no fue el único asunto relativo al Teatro en el que los ciudadanos de Medellín presentaban desacuerdos. Otro caso notorio fue la discusión sobre el mérito artístico del frontispicio del edificio, el cual para algunos conocedores era muy tradicional, poco acorde con el nuevo siglo. Pero lo más grave fue que, sólo tres años después de su inauguración, se manifestó la necesidad de ampliar el aforo del Teatro ${ }^{58}$.

Por aquella época, las empresas de espectáculos públicos asentadas en la ciudad ofrecieron comprarle al Concejo Municipal las acciones sobre el Teatro Bolívar, petición a la que se negó la corporación, al considerar inviable la propuesta de las compañías privadas ${ }^{59}$. Sin embargo, dichas empresas, junto con el Circo Teatro España y el Teatro Bolívar, aunaron fuerzas al año siguiente de dicha petición, para solicitarle al Concejo que considerara la posibilidad de disminuir los impuestos establecidos para los espectáculos públicos en el Acuerdo número 157 de 1922 que significaban un 5\%. El requerimiento contemplaba la propuesta de realizar el cobro no en forma de porcentaje, sino por medio de una cantidad fija para cada categoría de función, que supondría la condición del pago anticipado. Dicha propuesta fue negada por el Concejo en pleno, con el argumento de que el impues-

57 R., "A la empresa del Teatro", El Correo Liberal, 14 de septiembre, 1920, 1.

58 "Teatro Bolívar", El Colombiano, 15 de marzo, 1922, 2

59 A.H.M., fondo Actas del Concejo Municipal, tomo 326, folio 135v, 24 de abril, 1922. 
to era considerado razonable y equitativo y "porque la reglamentación dada a la recaudación del impuesto por espectáculos públicos subsana el inconveniente de pago anticipado por ellos acordado”60.

En la década de 1930, asumió la gerencia del Teatro Bolívar el promotor cultural Elías Gómez, quien junto con la Sociedad de Mejoras Públicas puso en marcha una serie de actividades culturales, como conferencias, conciertos, representaciones teatrales y "cine elegante", con el fin de convertir al escenario en un verdadero referente del arte local, en lugar de ser únicamente un espacio que se alquilaba sólo para la representación de grandes compañías de Teatro itinerantes y la proyección de películas comerciales ${ }^{61}$. El "cine elegante", proyectado en el Teatro Bolívar, respondía a una selección de cintas que perduraron por varias temporadas en los carteles de los teatros más importantes del mundo $^{62}$ y que no hacían parte de la programación habitual de las cerca de quince salas de cine destinadas de manera preferente a la exhibición de películas existentes en la ciudad al finalizar dicha década, entre ellas estaban el Teatro Don Bosco, el Teatro Junín, el Teatro Granada, el Teatro América, ${ }^{63}$ el Circo Teatro España, el Teatro María Victoria, el Teatro de Bellas Artes, el Teatro Alcázar, ${ }^{64}$ el Teatro Apolo, ${ }^{65}$ el Teatro Olympia ${ }^{66}$, el Teatro Colombia, ${ }^{67}$ el Salón España, ${ }^{68}$ una sala ubicada en el barrio Belén, el Teatro de El Sufragio, un salón para cine de los Salesianos y el Teatro Social.

Siguiendo en importancia al Teatro Bolívar, se encontraba el Teatro Junín, que se utilizaba frecuentemente para representaciones teatrales, aunque no exclusivamente. Había sido construido en 1924 por iniciativa del político y empresario Gonzalo Mejía, con un diseño encargado al arquitecto belga Agustín Goovaerts. El historiador Cenedith Herrera afirma que "se trataba de un espacio am-

60 A.H.M., Fondo Actas del Concejo Municipal, Tomo 333, Folio 78, 27 de febrero, 1923

61 "El Teatro Bolívar", El Colombiano, 17 de junio, 1932, 3.

62 Cronista, "Teatro Bolívar", El Colombiano, 13 de julio, 1933, 2.

63 Inició labores a mediados de 1930 en el barrio La América, bajo la administración de Jorge Salazar y patrocinado por el presbítero de la parroquia del lugar, Nicolás Ochoa. Diez años después, se levantó en aquel barrio el Teatro Santander. J. E. D. “Circo Teatro América", El Colombiano, 7 de mayo, 1930, 1.

64 Este teatro fue inaugurado en 1934 y estaba ubicado en la carrera Junín. Tenía una capacidad para mil trescientos espectadores, poseía silletería abullonada, iluminación indirecta, ventilación artificial y otras comodidades. "Condiciones arquitectónicas del Teatro Cinema Alcázar”, El Colombiano, Medellín, Número 6491, 5 de octubre, 1934, 1. Meses después de su estreno, el techo del Teatro colapsó, causando numerosas pérdidas humanas, así como grandes pérdidas económicas para los empresarios dueños de la sala. "La magna tragedia”, El Colombiano, 29 de enero, 1935, 1.

65 A mediados de 1934, se construyó el Teatro Apolo con capacidad para mil cuatrocientos espectadores y ubicado en la carrera Carabobo, acera oriental, entre las calles de la Paz y Vélez. Su propietario, Alejandro Ángel, un reconocido empresario local, fue testigo días antes del estreno del Coliseo, del desplome de la estructura, que dejó dos muertos y veinticuatro heridos. "El siniestro de ayer en el Apolo", El Colombiano, 8 de julio de 1934, 1.

66 El Teatro Olympia se inauguró en diciembre de 1935 y estaba ubicado en la carrera Carabobo, entre las calles de La Paz y Vélez, al parecer en el mismo lugar donde se levantó el Teatro Apolo. Poseía capacidad para albergar aproximadamente a mil cuatrocientas personas. "Los diversos aspectos del Teatro Olympia de Medellín”, El Colombiano, Medellín, Número 6915, 20 de diciembre de 1935,8 .

67 Este espacio se encontraba en la calle 50-Colombia, entre las carreras Giraldo y Bélgica, en el barrio Buenos Aires, frente a la manga de Los Puertas. Se inauguró en agosto de 1938, su construcción estuvo a cargo de la Casa de Ingenieros Tulio Ospina y Cía y contó con capacidad para recibir a mil seiscientos espectadores. “Teatro Colombia”, El Colombiano, 14 de agosto de 1938, 8.

68 Perteneciente al Circuito Antioquia y ubicado en la carrera de Sucre, entre Maracaibo y Caracas. 
plio en el que todos los medellinenses, gracias a la variedad de los precios de la boletería, gozaron de lo mejor del teatro y el cine, espectáculo este último del que los hermanos Di Domenico sacaron jugosa tajada de ganancias" ${ }^{\circ}$.

Pese a la trascendencia que alcanzó el Teatro Junín en la ciudad, el Teatro Bolívar aún seguía siendo considerado el "teatro elegante" y prestaba sus servicios a todo movimiento cultural que indicara "buen gusto, alto espíritu artístico, y refinamiento de buena ley"70. Los asistentes al Bolívar eran la expresión de los sectores acomodados de una ciudad a la que el desarrollo de la industria manufacturera había convertido en uno de los principales polos industriales de Colombia. Según el periódico El Colombiano, "frente al Bolívar forma un largo rosario de elegancia lo más lujoso y selecto de nuestro automovilismo ciudadano. Allí se quiebra el sol contra la cristalería de todas las marcas de lo más selecto en automóviles; prueba inequívoca de que al espectáculo asiste la élite de nuestra sociedad"71. Dicho teatro, considerado como el teatro público, de cuyo edificio era casi dueño en su totalidad el gobierno local, -que había adquirido unas últimas acciones en 1937 al señor Bernardo Echeverri $^{72}-$, el departamental y la Sociedad de Mejoras Públicas, estaba cumpliendo el cometido de consolidar un público compuesto por los pudientes e intelectuales que podían pagar los altos precios de la boletería, los cuales triplicaban el valor de una entrada corriente para el cine. En opinión de algunos periodistas, con la consolidación del cine entre las diversiones cotidianas, éste se convertiría en un espectáculo popular, a diferencia del teatro que "parece quedar para públicos más reducidos, selectos social o literariamente"73.

Sin embargo, la distancia entre el cine y el teatro se acortó, al menos espacialmente, cuando en 1939, el Bolívar se integró al Circuito Antioquia de cine, cuyo servicio de cinematógrafo era considerado el mejor de la época, debido a la instalación de un equipo sonoro R.C.A. Fotophone, el cual optimizó la imagen y el sonido ${ }^{74}$. A las adecuaciones necesarias para la prestación de cine, se sumó una petición de la Sociedad de Mejoras Públicas, la cual solicitó al Teatro que enllantara las alas de los palcos para evitar los ruidos durante el espectáculo ${ }^{75}$. Un año después, todos los teatros del país fueron sometidos por parte del gobierno nacional a una inspección rigurosa de todas sus instalaciones, a fin de evitar tragedias como las de Sandoná y Sogamoso, en las cuales perecieron algunos asistentes por falta de medidas de evacuación en casos de emergencia ${ }^{76}$.

69 Herrera, Cenedith. "Entre máscaras y tablas", 115.

70 Richard, "Del Teatro Bolívar”, El Colombiano, 18 de julio de 1933, 2.

71 Richard, "Del Teatro Bolivar", El Colombiano, 18 de julio, 1933, 2.

72 A.H.M, Fondo Actas del Concejo Municipal, tomo 373, folio 568, 31 de julio, 1937.

73 Larcegui, F., "El Teatro y el Cine", El Colombiano, 16 de julio, 1940, 5.

74 "El Teatro Bolívar abierto el veinte como cinematógrafo", El Colombiano, 15 de junio, 1939, 4.

75 "Se pide enllantar las alas de los palcos del Teatro Bolívar, ahora”, El Colombiano, 14 de noviembre, 1939, 2.

76 Jorge Gartner, “Se cerrarán los teatros que no ofrezcan hoy las garantías para la vida”, El Colombiano, 27 de septiembre, $1940,2$. 
La noticia de la integración del Teatro Bolívar al Circuito Antioquia no fue bien recibida por algunos sectores artísticos de la ciudad, entre ellos la Sociedad Amigos de las Bellas Artes, quienes instaban en dicho año al alcalde de la ciudad, Luis Mesa Villa, para que les entregara la administración del recinto, a fin de mejorar su suerte, teniendo en cuenta que era el único escenario dispuesto para representaciones diferentes de cine ${ }^{77}$. Seis años después, el municipio volvió a entregar la administración del Teatro Bolívar al Circuito Antioquia, para que fuera explotado por medio de la proyección cinematográfica. Esta vez se le obligaba al arrendatario a ceder seis días consecutivos del mes a la Junta Directiva de la Compañía del Teatro Bolívar, tres gratuitos y tres pagos, para fomentar la cultura y el arte; además estaban obligados a "mantener el teatro en una posición de primera categoría por la calidad y bondad de los espectáculos que se ofrezcan al público, y a no cederlo para conferencias políticas o partidistas que se relacionen con asuntos electorales o luchas de partidos"78.

Hacia 1942, el municipio de Medellín ya poseía la mayoría de las acciones del Teatro Bolívar, debido a que la Sociedad de Mejoras Públicas había conseguido que las comprara, al convencer a las autoridades de que un teatro público constituiría un beneficio cultural para la ciudad. Así, dos años antes, dicha Sociedad había vendido al Municipio sus 109 acciones por un valor de 545 pesos ${ }^{79}$. Pese a lo anterior, el Concejo Municipal manifestó su intención de vender sus derechos sobre el escenario, lo que causó consternación entre el público y la prensa local, cuyas quejas fueron escuchadas, pues el proyecto de Acuerdo, por el cual se autorizaba la venta fue finalmente archivado ${ }^{80}$.

Velando por la calidad y la mejor administración del teatro, el Concejo contrató la gerencia de la operación del mismo con diversas compañías, que debían comprometerse a llevar a escena "espectáculos culturales de primera clase, en lo que a cultura y arte se refiere, así como a la proyección de películas de estreno y seleccionadas, de casas filmadoras acreditadas, dando preferencia, claro está, a los conjuntos artísticos" $"$, de modo que en adelante las películas sólo se presentarían mientras no se encontrara en la ciudad alguna compañía de teatro.

No obstante, la comunidad artística, incluyendo a la Sociedad de Mejoras Públicas, la Sociedad Amigos del Arte y el Sindicato de Músicos y Cantantes de Medellín, se pronunciaron en varias ocasiones para exigir liberar al teatro del convenio con las empresas de perfil más comercial que artístico. Además, la prensa cultural insistía en que una ciudad próspera como Medellín tenía necesidad de un nuevo teatro destinado exclusivamente a las artes escénicas, debido a la permanente utilización del Bolívar como sala de cine y a que su tamaño ya no se ajustaba a la demanda de una población que

77 A.H.M., Fondo Alcaldía, serie Comunicaciones, tomo 13, folio 245, 30 de marzo, 1939.

78 A.H.M., Fondo Personería, sección Despacho, Serie Contratos, tomo 40, folio 92, 10 de mayo, 1945.

79 A.H.M., fondo Personería, sección Despacho, serie Contratos, tomo 40, folio 28, 22 de octubre, 1940.

80 Antonio Restrepo Arango, "La venta del Bolívar", El Colombiano, 11 de febrero, 1942, 5.

81 “Cuáles son las cláusulas principales del contrato de alquiler del Bolívar”, El Colombiano, 19 de mayo, 1945, 2. 
estaba por sumar trescientos mil habitantes. Los periodistas, citando las declaraciones del prestigioso empresario, líder cívico y promotor del teatro caleño Manuel María Buenaventura al periódico El Colombiano ${ }^{82}$ durante el Congreso Nacional de Historia en 1944, aseveraron que "Medellín, para

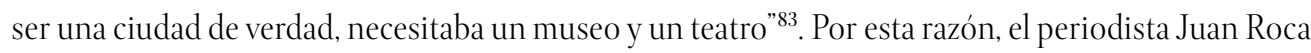
Lemus, más conocido como Rubayata, emprendió una campaña para la construcción de un teatro municipal moderno, obra que según el columnista: "al municipio de Medellín, se le hace sumamente factible la realización, [...] si se tiene en cuenta que este distrito capital es propietario de más de la mitad de las acciones del Teatro Bolívar. De suerte que le quedaría muy económico adquirir el resto de las acciones de esa compañía” ${ }^{84}$. El Municipio, en cabeza del alcalde Alberto Villegas Lopera, inició negociaciones para adquirir las 2.200 acciones, que aún estaban en manos de particulares, bajo la citada sociedad “Compañía del Teatro Bolívar”, de la cual hacía parte. A mediados de 1945, tan sólo le restaba comprar 200 acciones y en 1947 El Colombiano anunciaba que "el alcalde de Medellín sancionó el acuerdo [...], por medio del cual se le autoriza para proceder a la disolución y liquidación de la compañía del Teatro Bolívar de ésta ciudad, así como para la adopción de todas las medidas que sean indispensables para definir y hacer efectivos los derechos del municipio en dicho teatro" 85 .

\section{Un teatro público para Medellín: el ocaso del Teatro Bolívar}

Mientras el Municipio convertía el viejo Teatro Bolívar en un bien público, la prensa continuó su campaña en pro de un nuevo y moderno escenario, actualizando la vieja consigna del arte escénico como vehículo pedagógico con afirmaciones como: "el teatro, como complemento de la escuela, es base de la educación espiritual de los pueblos" ${ }^{\prime 86}$. Además, justificaron esta necesidad, argumentando que con un solo escenario de calidad era imposible que se presentaran simultáneamente en la ciudad varias compañías de gran envergadura, es decir, con un elenco numeroso, una indumentaria fastuosa y un repertorio con requerimientos especiales de acústica, como sucedió finalizando 1945 , cuando coincidieron en la ciudad las compañías Guzmán-Thorry, Hermanos Hernández y Argentina de Ópera, a cuyas representaciones asistió masivamente un público que, en varias ocasiones, se vio obligado a apreciar las funciones de pie, mientras los afortunados que alcanzaron asiento no podían salir libremente debido a la estrechez del espacio. Por lo cual la prensa afirmaba que "hasta por razo-

82 Manuel María Buenaventura visitó Medellín en el año de 1944 para participar en el Congreso Nacional de Historia. Fue Alcalde de Cali en varias ocasiones Secretario de Agricultura, de Hacienda y Director de Educación del Departamento del Valle del Cauca. Además, hizo parte de la junta constructora del Teatro Municipal de Cali. "Don Manuel María Buenaventura”, Diario del Pacífico, 5 de septiembre, 1946, 4.

83 “Otra vez el teatro", El Colombiano, 13 de marzo, 1944, 5.

84 "Acogida general tiene la iniciativa sobre un Teatro Municipal", El Colombiano, 6 de octubre, 1944, 2.

85 "Se disolverá la compañía que administra al Teatro Bolívar", El Colombiano, 25 de junio, 1947, 11.

86 Olimac, "En picada”, El Colombiano, 21 de octubre de 1945, 5. 
nes técnicas, pues, es aconsejable la construcción de un teatro moderno, acondicionado y suficiente, con todos los servicios indispensables" ${ }^{87}$.

La Sociedad de Mejoras Públicas se unió a la iniciativa a favor del teatro de los cronistas culturales, señalando que la mayoría de las salas de teatro de la ciudad estaban acondicionadas para cine y que el Teatro Bolívar era ya demasiado pequeño e incómodo, por lo que emprendería una "campaña cívica para la construcción de un gran teatro con el lujo o las comodidades propias de una ciudad que se preciaba de culta, civilizada y próspera" 88 .

Sin embargo, en agosto de 1947, el alcalde de Medellín, Eduardo Fernández Botero, designó una junta cívica para "estudiar la mejor fórmula de solución de lo que tan apropiadamente denominó "el problema del Teatro Bolívar" y para tratar sobre las posibilidades de construcción de un teatro moderno para Medellín” ${ }^{89}$. Meses después, el concejal conservador Antonio Osorio Isaza presentó a la corporación un proyecto de Acuerdo para la construcción de un teatro municipal90 ${ }^{90}$ el cual fue sancionado por el alcalde Juan Guillermo Restrepo Jaramillo en 1948 y se sumó a la celebración de los cincuenta años de la Sociedad de Mejoras Públicas, la cual contempló en su programa de conmemoración el apoyo a la iniciativa de edificación del nuevo escenario ${ }^{91}$.

Durante el año más álgido de la discusión sobre la construcción de un nuevo teatro, la ciudad albergó 440 funciones de diversos géneros, que sumaron un total de 206.279 espectadores y representaron económicamente ingresos por 317.287.62 pesos, con lo cual el teatro ocupó el segundo puesto -después del cine- entre los espectáculos más vistos durante 1947, lo que, según la prensa, se explicaba porque "muchas compañías imitan al cine y tienen como base la atracción, el éxito de la taquilla” ${ }^{2}$, entre ellas troupes como las de género policíaco. Entre tanto, se habían fundado en la ciudad varias salas de cine más: en 1940, el Teatro Avenida ${ }^{93}$; el Teatro Lido ${ }^{94}$; y el Teatro Santander ${ }^{95}$;

87 “Un teatro para Medellín”, El Colombiano, 22 de febrero, 1946, 5.

88 "La S. M. P. inicia campaña cívica por la construcción de un teatro moderno y de lujo para Medellín”, El Colombiano, 2 de marzo de 1946,2 .

89 "Por un teatro para Medellín”, El Colombiano, 23 de agosto, 1947, 5.

90 “Construcción de un Teatro Municipal propuso al Concejo el Dr. Osorio Isaza”, El Colombiano, 3 de febrero, $1948,2$.

91 "Medellín tendrá dentro de poco un magnífico teatro municipal”, El Colombiano, 9 de febrero, 1948, 2.

92 "En Medellín si existen lugares para diversión y recreo en días festivos", El Colombiano, 29 de marzo de 1948, 2.

93 Este teatro se construyó en la Avenida Primero de Mayo entre Junín y Palacé, hoy una sucursal de Bancolombia, por iniciativa del industrial Bernardo Mora. Tenía una capacidad para ochocientas personas y la novedad del escenario, fue que hizo parte de un centro comercial, pues contiguo a sus instalaciones se situaron: bar restaurante, almacenes, locales y vitrinas "En marzo se inaugura el Teatro Avenida", El Colombiano, 9 de febrero, 1940, 3.

94 Proyecto auspiciado por la firma F. L. Moreno y Compañía, quienes contrataron la firma de arquitectos Vásquez-Dothee, para que construyera el teatro en el costado oriental del Parque Bolívar. Fue arrendando a Cine Colombia, quienes en asocio con Caribe Films se encargaron de la exhibición de las películas. En la actualidad, es administrado por la Alcaldía de Medellín "Cineco estrena en Medellín su sala joya: El Lido”, Micro, Medellín, Número 1, 15 de febrero, 1940, 48-49). Cine Colombia fue fundada en 1927 y su éxito fue tal, que hacia 1946 controlaba más de cuatrocientos teatros en todo el país, siete de los cuales se encontraban en Medellín. “Más de cuatrocientos teatros controla hoy en la República la empresa de Cine Colombia”, El Colombiano, de mayo, $1946,9$.

95 El Teatro Santander se construyó en el barrio La América por el empresario Eusebio Salazar, quien contrató al arquitecto 
en 1943, los teatros Buenos Aires y Medellín; en 1945, Metro Avenida para proyectar películas de la Metro Goldwin Mayer y el Teatro Social Católico, ${ }^{96}$ y, en 1947, el Teatro Aranjuez que hizo parte del Circuito Medellín ${ }^{97}$ y el Teatro del Club Campestre; ${ }^{98}$ además, la empresa Cine Continental S. A. anunció su proyecto de construir cuatro teatros más en la ciudad. Fuera de las salas de cine, en 1944, el técnico cinematográfico M. Antonio García y otros fundaron una compañía filmadora de películas nacionales y una academia para actores de cine, pues pretendían "hacer unas ocho películas de largo metraje por año"99, proyecto que evidentemente no dio los resultados esperados.

En 1952, el administrador del Teatro Bolívar le solicitaba al alcalde de la ciudad, Jorge Ortiz Rodríguez, la suma de $\$ 150.000$ para la reconstrucción del teatro ${ }^{100}$, solicitud que se sumaba a una realizada meses antes por el mismo funcionario, en la cual se quejaba de la falta de presupuesto para llevar a cabo algunas reparaciones y para comprar chapas, escobas, bombillas, papel para escribir, entre otro tipo de utilería necesaria para el mantenimiento del recinto. Según su administrador, el ingeniero Bernardo Correa Machado, era urgente implementar algunas transformaciones, se necesitaba "nueva butaquería, instalar la Biblioteca Santander en el foyer superior, retirar los almacenes para ampliar el hall de entrada, [...] mejorar el escenario y los camerinos interiores, instalar sanitarios, aire acondicionado (o ventiladores al menos), cambiar de sistema de alumbrado, [...] conseguir mejor utilería y reparar la tramoya”101. Un año después, la Junta Cívica Municipal se sumó a la petición de reformas al teatro, que reunió con el alcalde para tratar entre otros asuntos, el del escenario.

Debido a las anteriores deficiencias señaladas por el administrador de aquella época y al deterioro detectado en el proceso de reparación del edificio, el 5 de noviembre de 1954 el periódico El Colombiano anunció la decisión de la Junta del Teatro Bolívar de demoler el inmueble, tras conocerse el informe de los ingenieros Alberto Vélez Escobar, Antonio Restrepo Álvarez y Javier Mora Mora, quienes aseguraron que la estructura presentaba serios problemas, los cuales podrían ocasionar un

\footnotetext{
Ignacio Ángel para la elaboración de los planos del edificio, el cual contó con una capacidad para alojar aproximadamente mil doscientos espectadores. Su inauguración fue a mediados de 1940. "El moderno Teatro Santander de La América se inaugura en julio", El Colombiano, 7 de mayo, 1940, 2.

96 Este espacio fue inaugurado a finales de 1945, estaba ubicado en la carrera Cundinamarca, entre las calles de Ayacucho y Pichincha. Se promocionó como un "centro de espectáculos [...] donde se dará preferencia a la moralidad y la cultura; un lugar adonde los padres podrán enviar a sus hijas y sus niños sin intranquilidades para sus conciencias de católicos". "Teatro Social Católico", El Colombiano, 23 de septiembre, 1945, 2.

97 “Hoy será inaugurado el moderno Teatro Aranjuez con Embrujo Antillano", El Colombiano, 19 de julio de 1947, 2.

98 Este espacio fue inaugurado en agosto de 1947 y estaba situado en el barrio de la Cooperativa de Habitaciones. "Teatro del Club Campestre", El Colombiano, 2 de agosto de 1947, 12.

99 "Surge la industria del cine en Medellín. Una gran academia será creada para la preparación de actores", El Colombiano, 10 de mayo, $1944,2$.

100 A.H.M., fondo Alcaldía, sección Despacho, serie Comunicaciones, tomo 94, folio 237, 2 de septiembre, 1952.

101 A.H.M., fondo Alcaldía, sección Despacho, serie Comunicaciones, tomo 94, folio 542-543, 6 de febrero, 1952)
} 
accidente si no se demolía completamente, pues no soportaría las reformas a las cuales ya estaba siendo sometida ${ }^{102}$. Según la comisión de técnicos:

Después de un detenido análisis de los diversos aspectos del problema, llegamos a la conclusión de que resultaría demasiado complicado y costoso intentar una reparación para conservar la sala sin modificar sus características esenciales. Tanto más cuando la estructura de esa parte de la edificación ya está terminando su vida económica y se ha empezado a desquiciar, quizá, esto último al faltarle los soportes que le daban las partes de la edificación que ya fueron demolidas.

Se ha insistido mucho en que debe conservarse la sala a toda costa, porque sus condiciones acústicas son excepcionales. Este punto mereció más completa atención pero francamente tenemos que manifestar a Ud. que no creemos posible asegurar que al terminar la reforma hoy planeada y en ejecución, aquellas condiciones acústicas originales se van a mantener, porque ellas, sin duda alguna, eran el resultado del conjunto de la edificación, sala y escenario y no de una sola de las partes constitutivas. Nosotros entendemos que será más fácil de lograr condiciones acústicas similares o iguales a las del antiguo Teatro Bolívar haciendo el planeamiento completo que planeado solamente una reforma como la que está en ejecución.

En vista de lo expuesto no dudaremos en conceptuar que:

1. Se suspendan los trabajos que se adelantan en la reforma del Teatro Bolívar.

2. Se termine la demolición y,

3. Se haga un planeamiento completo antes de continuar los trabajos de construcción ${ }^{103}$.

Frente a la decisión de demoler la principal y más representativa sala de teatro y artes escénicas de la ciudad, una parte de la ciudadanía, los centros cívicos locales y la Sociedad de Mejoras Públicas se pronunciaron a través de los diarios para exigir que se respetara la estructura. Además, conformaron una comisión para tratar ante la alcaldía municipal todo lo concerniente a la defensa del teatro ${ }^{104}$. Solicitaban, por lo menos, la construcción de un nuevo escenario en el mismo lugar, pues se rumoraba que el lote sería vendido para beneficio del municipio y que, según los planos reguladores de la ciudad, era necesario ensanchar la calle Ayacucho. Una de las peticiones más sentidas en favor del Teatro Bolívar fue la que un grupo de ciudadanos dirigió al alcalde municipal en los siguientes términos:

102 "Se convino en la demolición total del Teatro Bolívar", El Colombiano, Medellín, Número 13441, 5 de noviembre, $1954,1,18$.

103 “Se rindió el informe sobre la demolición del Teatro Bolívar”, El Colombiano, Medellín, Número 13442, 6 de noviembre, 1954,2 .

104 “Rehabilitación del Teatro Bolívar solicita la S. M. P., El Colombiano, 9 de noviembre, 1954, 13. 
Ante el peligro de ver desaparecer uno de los últimos lugares que dieron fisionomía de ciudad culta a nuestra querida Medellín que, por ser ciudad industrial se la piensa ciudad mercantilizada y desentendida de las bellas artes y disciplinas espirituales que no respeta tradición, ni tiene amor por las cosas que representan el comienzo de nuestra historia civil, acudimos a su autorizado criterio, para que nos ayude con su poderosa influencia a evitar, a toda costa, la demolición total del Teatro Bolívar ${ }^{105}$.

Pese a las solicitudes y los pronunciamientos públicos, el Teatro se terminó de demoler el 3 de diciembre de 1954, ante los ojos atónitos de quienes conservaban la esperanza de que el gobierno local reconsiderara el decreto. Días después, se anunció que el alcalde Darío Londoño Villa estaba adelantando negociaciones con los dueños del Circo La Macarena para cambiar el terreno donde estaba construido el Teatro Bolívar, por el citado circo y los terrenos adyacentes. Según El Colombiano, "los nuevos propietarios de los terrenos del Bolívar se comprometerían a construir en ese mismo lugar un teatro de especificaciones parecidas al que existía alli”106. Sobre el tema no se habló más, la ciudad no volvería a contar con un Teatro adecuado para representaciones escénicas de todo género hasta cinco años más tarde, cuando la Sociedad de Mejoras Públicas lideró el proyecto de construcción de un nuevo escenario privado, el Teatro Pablo Tobón Uribe, que se inauguró a mediados de $1960^{107}$.

\section{Imagen 4: Teatro Bolívar en proceso de demolición}

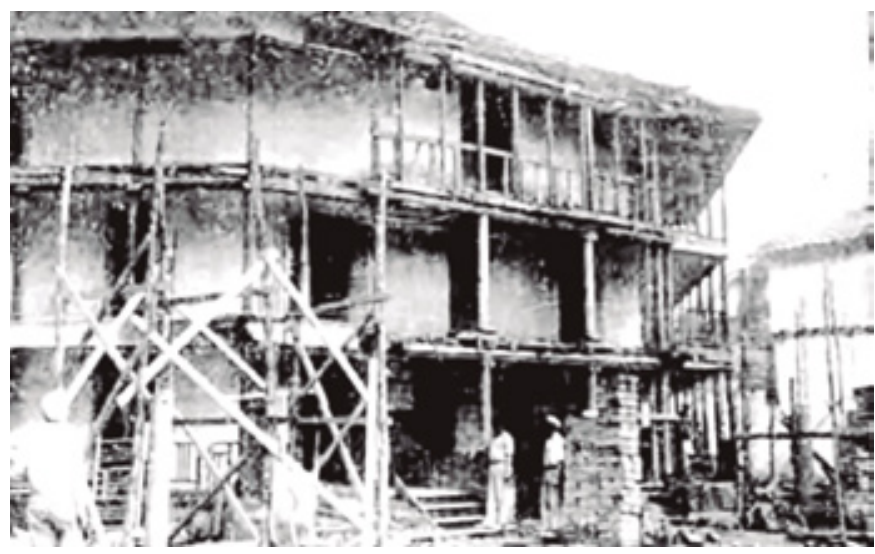

Fuente: El Colombiano, Medellín, noviembre 12 de 1954, número 13.448, p. 3.

Finalmente, con el objetivo de recuperar algún mobiliario importante del Teatro Bolívar, la Sociedad de Mejoras Públicas solicitó al alcalde municipal que se sirviera donar, para el Teatro de Bellas

105 A.H.M., fondo Alcaldía, sección Despacho, serie Comunicaciones, tomo 103, folio 509, 10 de noviembre de 1954.

106 “El municipio adquirirá el Circo de la Macarena”, El Colombiano, 4 de diciembre, 1954, 1.

107 Cenedith Herrera, “Entre máscaras y tablas”, 116. 
Artes y para las escuelas de teatro, el telón de boca, las cortinas y otros implementos importantes ${ }^{108}$, los cuales desaparecieron en su totalidad con el transcurrir del tiempo.

\section{Conclusiones}

En el presente artículo se ha intentado contribuir al conocimiento sobre los espacios para las prácticas y las representaciones escénicas en Medellín entre la segunda mitad del siglo XIX y la primera del XX. A través del recorrido por las trasformaciones de espacios teatrales de la ciudad, se buscó comprender el significado social del Teatro Bolívar y de otros espacios para las actividades teatrales y de ocio, señalando que la sociedad de Medellín durante este periodo se sirvió del teatro para construir una representación de sí misma, un entendimiento de lo social y una interpretación de sus relaciones con el mundo.

Como se señaló antes, el primer edificio de este tipo se construyó por iniciativa privada en 1836 , en cabeza del médico Pedro Uribe Restrepo, y se llamó Coliseo Principal. Durante su existencia (1836-1919) fue objeto de múltiples adecuaciones, conforme al deterioro del mismo y a las necesidades de los espectadores, los cuales aumentaban a medida que la población crecía. Este espacio manifiesta el propósito de las élites locales de convertir a Medellín en una ciudad moderna, en la cual el teatro estaba destinado a ser uno de los parámetros capitales para leer el grado de "progreso" y de “civilización” de la sociedad, que se gestó en el transcurso del paso del siglo XIX al XX.

Sobre las ruinas del viejo Coliseo, se erigió el Teatro Bolívar en 1919, proyecto que contó con capital privado y público, inversión mixta que se mantuvo hasta mediados del siglo XX, cuando la administración municipal adquirió todas las acciones del teatro. Así, con la inauguración de este espacio y con la compra, por parte del municipio, de la totalidad de las acciones, se dio inicio a una nueva etapa del auditorio, el cual tuvo que ser entregado en varias ocasiones para su administración a los circuitos de cine locales por falta de capital para su promoción en beneficio de los habitantes de Medellín.

Así, se han podido delimitar tres etapas en la existencia de este espacio escénico en Medellín: una inicial en el siglo XIX, donde la iniciativa es exclusivamente privada; un segundo momento en el que se puede observar una naturaleza mixta, que combinaba los intereses privados y públicos; y una tercera etapa, ya en los años cuarenta, en la cual el Teatro quedó a merced del gobierno municipal, lo que coincidió con un declive evidente y su posterior demolición. Aparte del Coliseo y del Teatro Bolívar, a lo largo del artículo también se han mencionado otros espacios dispuestos para las representaciones escénicas en Medellín, buscando indicar su aparición, su transformación y la trascendencia que

108 A.H.M., fondo Alcaldía, sección Despacho, serie Comunicaciones, tomo 103, folio 123, 19 de agosto, 1958. 
alcanzaron dichos escenarios en el acontecer cultural local, del cual fueron testigos y protagonistas. En las tres etapas señaladas fue notable el interés en la importancia de las artes escénicas para educar y entretener al pueblo, ávido, según las élites económicas y políticas, de diversiones altamente moralizantes.

\section{Referencias bibliográficas}

\section{Fuentes primarias/documentales}

Fuentes manuscritas:

Archivo Histórico de Medellín (AHM), Medellín, Colombia. Fondos: Actas del Concejo Municipal, Alcaldía-Serie Comunicaciones, Personería-Sección Despacho, Serie Contratos. Archivo Histórico de Antioquia (AHA), Medellín, Colombia. Fondos: Notaria Primera, Notaria Tercera.

\section{Fuentes impresas}

\section{Publicaciones periódicas:}

Antioquia, Medellín, 1857-1858.

Colombia, Medellín, 1919.

Diario del Pacífico, Cali, 1946.

El Ciudadano, Medellín, 1875.

El Colombiano, Medellín, 1912-1960.

El Conservador, Medellín, 1911.

El Correo de Antioquia, Medellín, 1864, 1899.

El Correo Liberal, Medellín, 1920, 1922-1923.

El Espectador, Medellín, 1887-1904, 1919-1920, 1922-1923.

El Índice, Medellín, 1865-1870.

El Liceo Antioqueño, Medellín, 1884.

El 5 de Abril, Medellín, 1877-1878.

Helios, Medellín, 1907-1909.

La Balanza, Medellín, 1880.

La Luneta, Medellín, 1906.

Las Novedades, Medellín, 1877-1878, 1893-1910.

Sábado, Medellín, 1922-1929.

Letras y Encajes, Medellín, 1926-1956.

\section{Libros:}

Saffray, Charles. Viaje a Nueva Granada. Bogotá. Ministerio de Educación Nacional: 1948.

Gónima, Eladio. Historia del teatro de Medellín yvejeces. Medellín: Ediciones Tomás Carrasquilla, 1973. 
Ochoa, Lisandro. Cosas viejas de la villa de la Candelaria. Medellín: Colección Autores Antioqueños, Vol. 8, 1984.

Silva, Isidoro. Primer directorio general de la ciudad de Medellín, para el año de 1906. Medellín: Instituto Tecnológico Metropolitano, 2003.

\section{Bibliografía consultada}

Ceballos Gómez, Diana Luz. Prácticas, territorios y representaciones en Colombia, 1849-1960. Medellín: Universidad Nacional de Colombia, 2009.

Correa Serna, Nancy Yohana. “Teatro y sociedad en Medellín, 1880 -1910”. Tesis de pregrado, Programa de Historia, Universidad de Antioquia, 2004.

Correa Serna, Nancy Yohana. "Mujeres en escena. De Susana Tirado a Marina Ughetti”. Tesis de Maestría en Historia, Universidad Nacional de Colombia, sede Medellín, 2015.

Gómez Espinosa, Jaime Alberto. “Ordenando el orden: la policía en Medellín 1826-1914. Funciones y estructuras". Tesis de Maestría en Historia, Universidad Nacional de Colombiasede Medellín, 2012.

González, Luis Fernando. "La fisiología de la ciudad: médicos e ingenieros en el Medellín de hace un siglo". Iatreia, 16: 1 (2006): 77 - 94.

Herrera, Cenedith. “Entre máscaras y tablas. Teatro y sociedad en Medellín, 1890-1950”. Tesis de pregrado, Programa de Historia, Universidad Nacional de Colombia- Sede Medellín, 2005. Lamus Obregón, Marina. Teatro siglo XIX. Compañías nacionales y viajera. Bogotá: Editorial Kimpre, 2004.

Londoño Vega, Patricia. "Vida diaria en Antioquia durante el siglo XX”. En: MELO, Jorge Orlando (editor). Historia de Antioquia, Medellín: Suramericana de Seguros. 1987. 